Editorial

\title{
The role of organic matrices in biomineralization
}

\author{
Nils Kröger ${ }^{1}$ Eike Brunner ${ }^{1} \cdot$ Lara Estroff $^{2} \cdot$ Frédéric Marin $^{3}$
}

Published online: 17 December 2021

(c) The Author(s) 2021 OPEN

The biological formation of inorganic materials-a process called biomineralization-is a widespread phenomenon that occurs throughout the evolutionary tree of life [1]. Biomineral forming organisms are amazingly adept at producing inorganic materials with complex morphologies and extraordinary properties [1-4]. Prominent examples are the single domain magnetite nanocrystals of bacteria that act as sensitive magnetic field sensors [5], the hierarchically porous silica-based cell walls of diatoms exhibiting complex photonic properties [6-8], and the nacreous calcium carbonate layers of mollusks with exceptionally high fracture resistance [9]. The mesmerizing morphologies of biominerals unveil our incomplete understanding of the physical and chemical forces that drive mineral morphogenesis (Fig. 1). Elucidating how organisms are able to produce minerals with complex shapes is a key aim in biomineralization research, and has the potential to inspire sustainable routes for the production of new materials with advanced properties [10].

At the same time, the ubiquitous occurrence of biomineralization influences the geochemical cycling of several elements on a global scale. In particular, calcium carbonate and hydrated silicon dioxide (silica) are the two most abundant biominerals occurring in a wide variety of taxonomic groups including bacteria, protists and multicellular organisms [1]. Understanding the cellular factors that control calcium carbonate and silica biomineralization and how they are influenced by environmental factors is therefore important to obtain a full understanding of the elemental fluxes of calcium, silicon and carbon in many ecosystems.

The Topical Collection "The Role of Organic Matrices in Biomineralization" is concerned exclusively with examples taken from calcium carbonate and silica biomineralization. Biological calcium carbonate occurs predominantly in the three crystalline polymorphs (calcite, aragonite, vaterite), whereas biological silica is always amorphous [1]. Despite the differences in crystallinity and chemistry of calcium carbonate and silica biominerals, past research has revealed similarities between them:

(i) The biogenesis of most—if not all—crystalline calcium carbonate biominerals proceeds via a transient amorphous phase (ACC) [11].

(ii) Biosilica and biogenic carbonates contain tightly associated organic matrices composed of polysaccharides and/ or (glyco-)proteins [12-15].

(iii) Complete dissolution of the biomineral under non-hydrolytic conditions separates the organic matrix into a soluble and an insoluble fraction $[15,16]$.

(iv) The organic matrices of biominerals contain exceptionally high proportions of proteins with intrinsically disordered domains $[12,14,17]$.

The idea for this Topical Collection originated from the Research Unit FOR2038 ("Nanomee"), which was funded by the German Research Foundation (DFG) from 2014-2021. The aim of Nanomee was to investigate the role of organic

$\square$ Nils Kröger, nils.kroeger@tu-dresden.de| ${ }^{1}$ Technische Universität Dresden, Dresden, Germany. ${ }^{2}$ Cornell University, Ithaca, USA. ${ }^{3}$ Université de Bourgogne - Franche-Comté, Franche-Comté, France. 

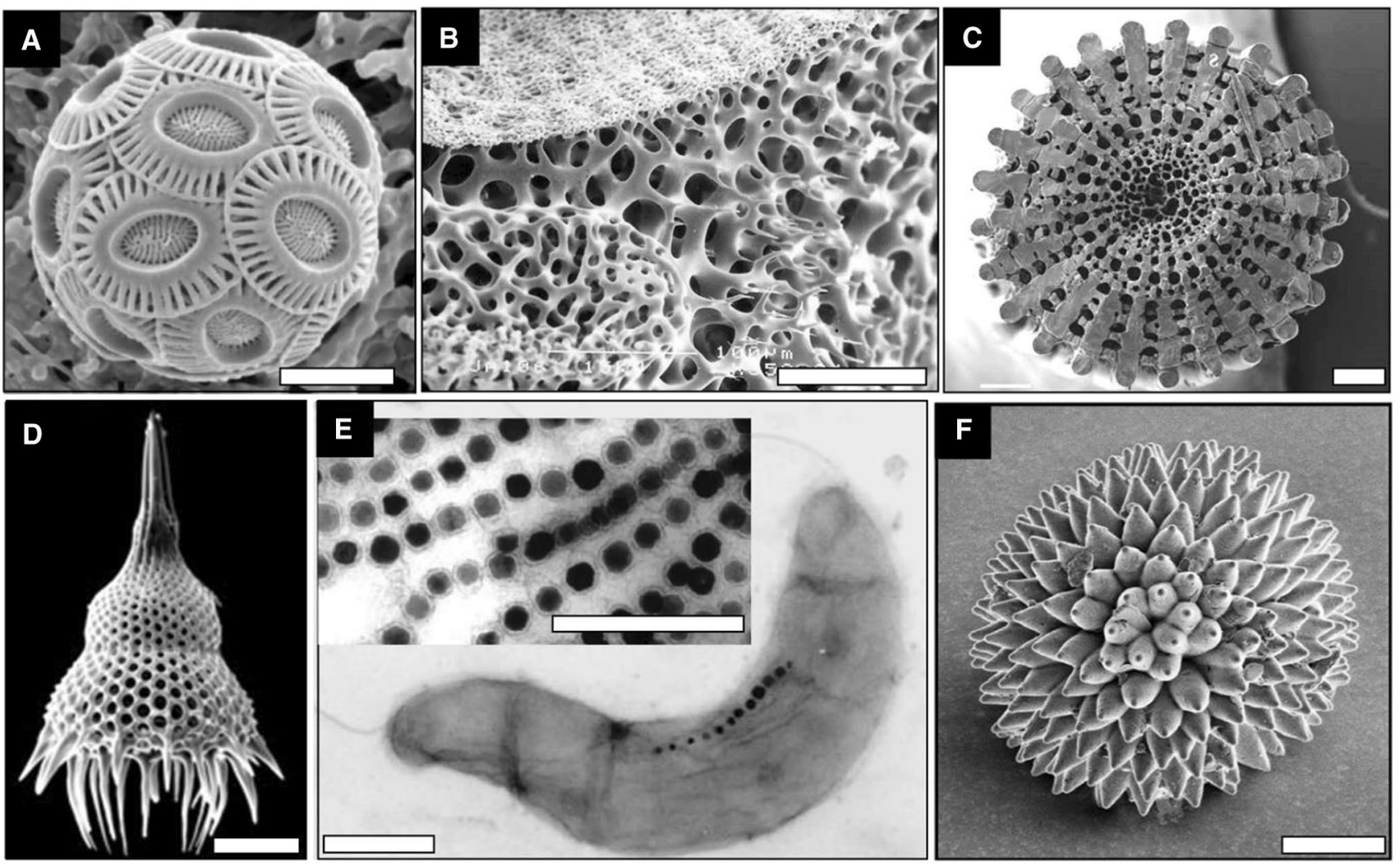

Fig. 1 Biominerals. Scanning (A-D, F) and transmission (E) electron microscopy images of $\mathrm{CaCO}_{3}$-based $(\mathbf{A}-\mathbf{C})$, $\mathrm{SiO}_{2}$-based $(\mathbf{D}, \mathbf{F})$, and $\mathrm{Fe}_{3} \mathrm{O}_{4}$-based (E) biominerals. A Cell wall of an individual cell of Emiliania huxleyii, a species of coccolithophore (courtesy of J. Young, UCL, UK). B Typical stereom structure of an echinoderm (sea urchin) skeleton (courtesy of J. Aizenberg, Harvard University, USA). C Transverse section of the primary spine of a sea urchin (courtesy of P. Dubois, Université Libre de Bruxelles, Belgium). D Endoskeleton of an individual cell of the radiolaria Lamprocyclas martialis (courtesy of J. Dolven, www.radiolaria.org). E Individual cell of Magnetospirillum gryphiswaldense containing a single chain of biomagnetite nanocrystals; inset: isolated biomagnetite nanocrystals (courtesy of D. Schüler, Universität Bayreuth, Germany). F A microsclere from the demosponge Geodia cydonium (courtesy of I. Zlotnikov, Technische Universität Dresden, Germany). Scale bars: $2 \mu \mathrm{m}(\mathbf{A}), 100 \mu \mathrm{m}(\mathbf{B}, \mathbf{C}), 50 \mu \mathrm{m}$ (D), $500 \mathrm{~nm}(\mathbf{E}), 10 \mu \mathrm{m}(\mathbf{F})$

matrices in the morphogenesis of the intricate, species specific silica structures that are produced by diatoms (Fig. 2) [18]. Diatoms are a large group of unicellular, eukaryotic algae that are present in all water habitats, and their photosynthetic activity accounts for $20 \%$ of the biological primary production in all oceans. Since the Cretaceous, they are key players in the geochemical cycles of both carbon and silicon [3]. To date, diatoms have emerged as the prime model systems for studying the molecular underpinnings and mechanisms of biological silica formation. Numerous species of diatoms are available that can be easily cultured in the lab, an increasing number of diatom genome and transcriptome databases have been generated, and methods for their genetic manipulation have been established [19]. These tools provide key experimental advantages over the large number of other groups of organisms that produce biosilica.

In this Topical Collection, Nanomee research groups present eight original papers and one review article on the role of biomacromolecules diatom biosilica formation. These reports are complemented by two original papers and two review articles on calcium carbonate biomineralization in bacteria, corals, snails, and birds. Altogether the contributions are grouped into three larger research topics:

\section{Cellular and tissue organization}

Neri Fattorini \& Uwe G. Maier. Targeting of proteins to the cell wall of the diatom Thalassiosira pseudonana.

Sigrid Görgen et al. The diversity of molecular mechanisms of carbonate biomineralization by bacteria.

J. Gautron et al. Avian eggshell biomineralization: an update on its structure, mineralogy and protein tool kit. 

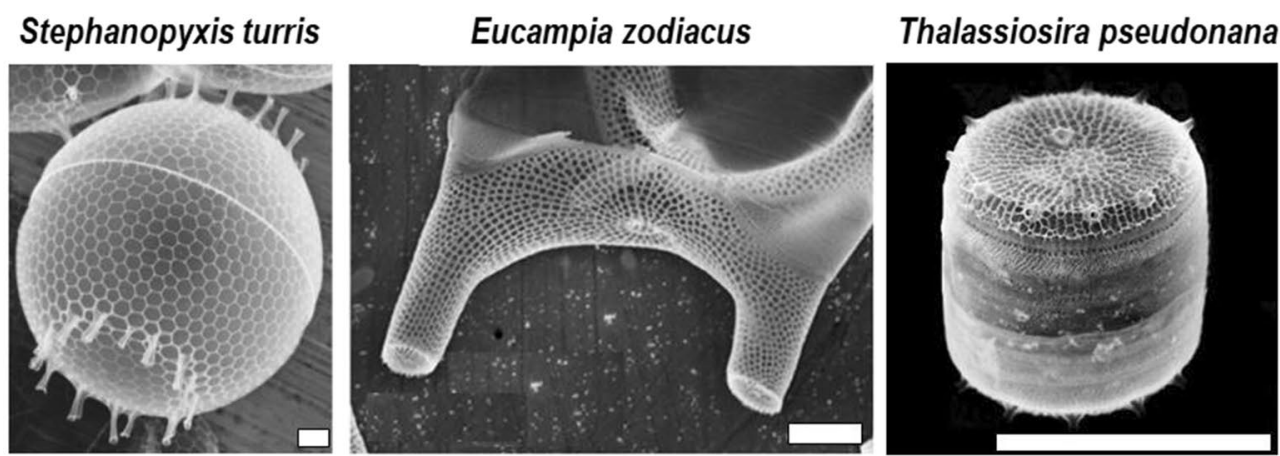

Cyclotella cryptica
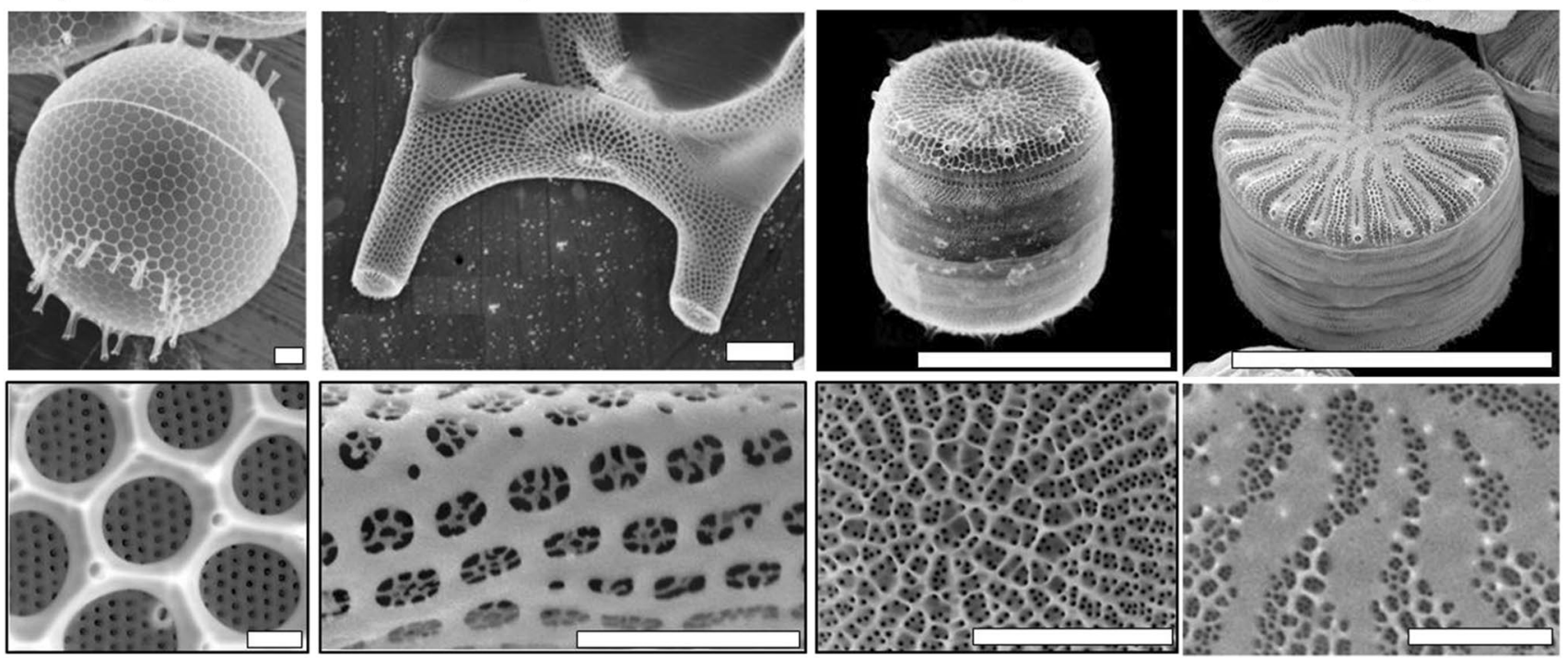

Fig. 2 Scanning electron microscopy images of overviews (top) and corresponding details (bottom) of the biosilica from individual cells of different diatom species. Scale bars: $5 \mu \mathrm{m}$ (top), $1 \mu \mathrm{m}$ (bottom)

\section{Biochemical, biophysical, and molecular genetic analysis}

Christoph Heintze et al. An intimate view into the silica deposition vesicles of diatoms.

Felicitas Kolbe et al. Solid-state NMR spectroscopic studies of ${ }^{13} \mathrm{C}_{1}^{15} \mathrm{~N},{ }^{29} \mathrm{Si}$-enriched biosilica from the marine diatom Cyclotella cryptica.

Helena Leona Ehren et al. DNP-supported solid-state NMR studies of ${ }^{13} \mathrm{C}_{1}^{15} \mathrm{~N}^{29}$ Si-enriched biosilica of Cyclotella cryptica and Thalassiosira pseudonana.

Adeeba Fathima et al. Precision of fiducial marker alignment for correlative super-resolution fluorescence and transmission electron microscopy.

Martin Wustmann et al. Chitin synthase localization in the diatom Thalassiosira pseudonana.

Yanai Peled et al. Optimization of skeletal protein preparation for LC-MS/MS sequencing yields additional coral skeletal proteins in Stylophora pistillata.

Nicolas Cerveau \& Daniel John Jackson. A survey of miRNAs involved in biomineralization and shell repair in the freshwater gastropod Lymnaea stagnalis.

\section{Computational analysis and modeling}

Hagen Eckert et al. Exploring the organic-inorganic interface in biosilica: atomistic modeling of polyamine and silica precursors aggregation behavior.

Szabolcs Horvát et al. Computational analysis of the effects of nitrogen source and $\sin 1$ knockout on biosilica morphology in the model diatom Thalassiosira pseudonana.

Manfred Bobeth et al. Continuum modelling of structure formation of biosilica patterns in diatoms.

The purpose of this Topical Collection is to highlight that the biomineralization mechanisms of models that are biologically and chemically very different can be addressed through similar experimental approaches and methodologies. Furthermore, we want to raise awareness about the importance of identifying mechanistically conserved strategies that exists in biomineralization. Such insight is not only key to understanding the mechanisms and evolutionary history of biomineralization, but is also required to foster the development of untraveled routes for composite materials synthesis.

Open Access This article is licensed under a Creative Commons Attribution 4.0 International License, which permits use, sharing, adaptation, distribution and reproduction in any medium or format, as long as you give appropriate credit to the original author(s) and the source, 
provide a link to the Creative Commons licence, and indicate if changes were made. The images or other third party material in this article are included in the article's Creative Commons licence, unless indicated otherwise in a credit line to the material. If material is not included in the article's Creative Commons licence and your intended use is not permitted by statutory regulation or exceeds the permitted use, you will need to obtain permission directly from the copyright holder. To view a copy of this licence, visit http://creativecommons.org/licenses/by/4.0/.

\section{References}

1. Lowenstam HA, Weiner S. On biomineralization. Oxford: Oxford University Press; 1989.

2. Bäuerlein $\mathrm{E}$, editor. Biomineralization: from biology to biotechnology and biomedical application. 2nd ed. Weinheim: Wiley-VCH; 2004 .

3. Dove PM, De Yoreo JJ, Weiner S, editors. Biomineralization. Reviews in mineralogy and geochemistry, vol. 54. Chantilly: Mineralogical Society of America; 2003.

4. Meldrum FC, Cölfen H. Controlling mineral morphologies and structures in biological and synthetic systems. Chem Rev. $2008 ; 108: 4332$.

5. Faivre D, Schüler D. Magnetotactic bacteria and magnetosomes. Chem Rev. 2008;108:4875.

6. De Tommasi E, et al. UV-shielding and wavelength conversion by centric diatom nanopatterned frustules. Sci Rep. $2018 ; 8: 16285$.

7. Goessling JW, et al. Structure-based optics of centric diatom frustules: modulation of the in vivo light field for efficient diatom photosynthesis. New Phytol. 2018;219:122.

8. Fuhrmann T, et al. Diatoms as living photonic crystals. Appl Phys B-Lasers O. 2004;78:257-60.

9. Sun J. Bhushan B Hierarchical structure and mechanical properties of nacre: a review. RSC Adv. 2012;2:7617.

10. Kröger N. Brunner E Complex-shaped microbial biominerals for nanotechnology. WIREs Nanomed Nanobiotechnol. $2014 ; 6: 615$.

11. Addadi L, et al. Taking advantage of disorder: amorphous calcium carbonate and its roles in biomineralization. Adv Mater. 2003;15:959.

12. Marin F. Mollusc shellomes: past, present and future. J Struct Biol. 2020;212:107583.

13. Evans JS. The biomineralization proteome: protein complexity for a complex bioceramic assembly process. Proteomics. 2019;19:e1900036.

14. Taylor AR, et al. Coccolithophore cell biology: chalking up progress. Ann Rev Mar Sci. 2017;9:283.

15. Otzen D. The role of proteins in Biosilicification. Scientifica. 2012. https://doi.org/10.6064/2012/867562.

16. Hildebrand $M$, et al. Understanding diatom cell wall silicification-moving forward. Front Mar Sci. 2018;5:125.

17. Skeffington $A$ et al. Shedding light on biosilica morphogenesis by comparative analysis of the silica-associated proteomes from three diatom species bioRxiv 2021.09.18.460806

18. https://www.nanomee.de/

19. Falciatore A, et al. Diatom molecular research comes of age: model species for studying phytoplankton biology and diversity. Plant Cell. 2020;32:547.

Publisher's Note Springer Nature remains neutral with regard to jurisdictional claims in published maps and institutional affiliations. 